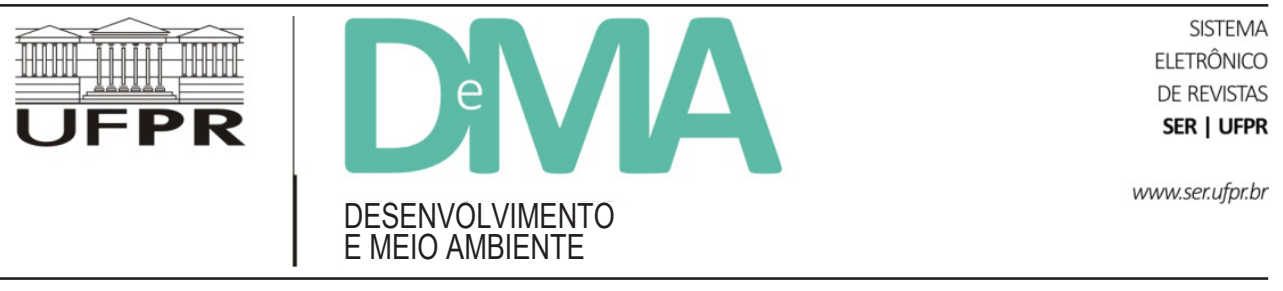

\title{
O Programa Produtor de Água e Floresta de Rio Claro/RJ enquanto ferramenta de gestão ambiental: o perfil e a percepção ambiental dos produtores inscritos ${ }^{1}$
}

\section{The Program "Produtor de Água e Floresta" in Rio Claro/RJ as a Tool for Environmental Management: The Profile and Environmental Awareness of Participant Producers}

\author{
Roberta Fernanda da Paz de Souza PAIVA ${ }^{1 *}$, Rafael Campos COELHO ${ }^{1}$ \\ ${ }^{1}$ Departamento de Engenharia de Agronegócios, Universidade Federal Fluminense (UFF), Volta Redonda, RJ, Brasil. \\ "E-mail de contato: robertapaz2003@yahoo.com.br
}

Artigo recebido em 1 de junho de 2014, versão final aceita em 19 de fevereiro de 2015.

RESUMO: O pagamento por serviços ambientais (PSA) é uma ferramenta que vem sendo adotada com vistas a estimular a adoção, por parte dos produtores rurais, de ações que possam contribuir para a recuperação e a preservação ambientais por meio da adesão voluntária em programas de conservação. Uma das experiências de PSA já implantadas no Brasil é o Programa Produtor de Água e Floresta (PAF) da cidade de Rio Claro/RJ, área estratégica para o fornecimento de água para a cidade do Rio de Janeiro e região metropolitana. Por meio do PAF, produtores rurais são remunerados financeiramente pela "oferta" de serviços ambientais. Sendo um programa de adesão voluntária, faz-se necessário o estudo de variáveis que possam contribuir para um maior número de adesões e a efetividade de seus resultados. Com vistas a contribuir para a avaliação e validação do mesmo, este estudo tem como objetivo discutir de que maneira o perfil socioeconômico, a percepção quanto à sustentabilidade ambiental e serviços ecossistêmicos e a consciência ambiental dos produtores que integram o PAF determinaram sua adesão. Pretende-se ainda avaliar, por meio da percepção dos mesmos, a implantação do programa e seus resultados. Para tanto, foram aplicadas entrevistas semiestruturadas a 29 dos 59 produtores integrantes. Os resultados indicam que a maioria dos produtores que aderiu ao projeto já adotava práticas de conservação e optou em participar pela consciência ambiental que já tinham. Isso mostra a necessidade de se estimular proprietários que ainda não sejam adeptos de tais práticas a integrar o projeto, elevando seu ganho marginal. Segundo os produtores, os valores pagos são baixos e acabam por não estimular a adesão de novos integrantes. Observa-se ainda que o grupo considerado percebe o meio ambiente como determinante para o seu bem-estar, de sua família e de outras espécies, dando importância, portanto, aos serviços ecossistêmicos que os afetam direta ou indiretamente.

Palavras-chave: gestão das bacias hidrográficas; pagamento por serviços ambientais; serviços ecossistêmicos.

1 Este estudo foi financiado pela Associação Pró-Gestão das Águas da Bacia Hidrográfica do Rio Paraíba do Sul - AGEVAP por meio do Edital AGEVAP 02/2012. 
ABSTRACT: The payment for ecosystem services (PES) is a tool that has been adopted to stimulate the taking of actions that can contribute to the environmental recovery and preservation by means of the voluntary participation in conservation programs by farmers. One of the PES experiences already implemented in Brazil is the Program "Produtor de Água e Floresta" in the city of Rio Claro/RJ, a strategic area for the supply of water to the city of Rio de Janeiro and its metropolitan area. Through PES, rural producers are paid for the provision of ecosystem services. As it is a voluntary participation program, it is important to study the variables that can contribute to increase the number of participants and the program effectiveness. The purpose of this study is to discuss the social and economic characteristics, the perception regarding environmental sustainability and ecosystem services, the environmental awareness of farmers who are participating in the PES under study, as well as the conditioning factors that influence farmers' participation. Moreover, we intend to assess the implementation of the program and its results. We have conducted semi-structured interviews with 29 out of 59 participating farmers. Results indicate that most o farmers who took part in the project already adopted conservation practices and chose to participate led by the environmental awareness they already had. This shows the need to stimulate other farmers who have not yet adopted such practices to participate in the project, elevating their marginal earnings. According to the farmers, amounts paid are low and do not stimulate adhesion by new members. We also noticed that the group under study see the environment as crucial for their, their families and other species' well-being, understanding the importance of ecosystem services that directly or indirectly affect them.

Keywords: water basin management; payment for ecosystem services; ecosystem services.

\section{Introdução}

O recurso hídrico apresenta-se atualmente como um dos recursos naturais mais escassos e disputados. A pressão exercida pela ação humana, em conjunto com os fatores climáticos, vem contribuindo para a redução de sua disponibilidade em termos de quantidade e qualidade.

Apesar de no Brasil se obterem níveis satisfatórios de disponibilidade de água per capita, tem-se que sua distribuição espacial é desigual no território. Cerca de $80 \%$ da disponibilidade hídrica do país está concentrada na região hidrográfica amazônica, onde se encontram o menor contingente populacional $(5 \%$ da população brasileira) e a menor demanda consuntiva. Além disso, os piores níveis de qualidade se encontram, em sua maioria, em corpos hídricos que atravessam áreas urbanas densamente povoadas, como regiões metropolitanas e grandes cidades do interior (ANA, 2013).

Os usos aos quais destinam a água são imprescindíveis ao atendimento das condições de bem-estar humano, esteja esse a ela associado de maneira direta ou indireta. A intervenção humana por meio da utilização para abastecimento (urbano, rural e industrial), irrigação, criação de animais, como receptor de esgotos (tratados ou não), produção de energia, navegação, pesca e turismo, entre outros, permite que se alcancem condições satisfatórias para a manutenção da qualidade de vida humana, mas, ao mesmo tempo, impacta de maneira negativa os recursos hídricos em termos de quantidade e qualidade e, consequentemente, a sobrevivência dos ecossistemas que deles dependem (MEA, 2005).

Dessa forma, a degradação dos recursos naturais impede que os mesmos possam exercer suas funções, não sendo garantido, portanto, o provimento de bens e serviços ecossistêmicos necessários à manutenção da vida humana e de outras espécies, para a atual e futuras gerações.

Segundo De Groot et al. (2002), as funções do ecossistema podem ser definidas como a capacidade dos processos e componentes naturais de fornecer bens e serviços que satisfaçam as necessidades humanas direta ou indiretamente. Para estes autores, cada função é o resultado dos processos naturais do subsistema ecológico do qual ela faz parte, sendo os processos naturais um resultado de interações complexas entre componentes bióticos e abióticos dos ecossistemas por meio das forças dirigentes de matéria e energia.

Assim, como complementam Costanza et al. (1997), os bens (tais como alimentos) e serviços (tais 
como assimilação dos resíduos) do ecossistema representam os benefícios dos quais as populações humanas desfrutam (derivam), direta ou indiretamente, das funções do ecossistema.

Daly \& Farley (2003), ao conceituar funções e serviços ecossistêmicos, ressaltam ainda a dependência entre economia e meio ambiente. Segundo eles, é impossível criar alguma coisa a partir de coisa alguma; já que toda produção econômica requer um fluxo de recursos naturais gerados pelo estoque de capital natural. Dessa forma, toda produção requer matéria-prima da estrutura ecossistêmica. A estrutura ecossistêmica gera funções ecossistêmicas, que fornecem serviços e toda produção econômica gera impactos nos serviços ecossistêmicos.

Os conceitos apresentados pressupõem a existência de processos baseados na integração/interação complexa entre as diversas partes de um todo, caracterizando-os como imprescindíveis à conservação das diversas "partes" com vistas à proteção das funções desenvolvidas pelo "todo".

Nesse contexto, a degradação das estruturas por meio da intervenção humana pode trazer consequências espaciais e temporais, afetando o bem-estar humano em seus diversos componentes, a saber: a segurança, o acesso a bens materiais para uma vida boa, a saúde, as relações sociais e as liberdades e opções de escolha (MEA, 2005).

Esses componentes são diretamente afetados por perdas nos serviços ecossistêmicos, como os serviços de abastecimento (produtos obtidos dos ecossistemas: alimentos, água potável, combustível, etc.); os serviços de regulação (benefícios obtidos pela regulação dos processos dos ecossistemas: regulação do clima, das enfermidades, da água, entre outros); os serviços culturais (benefícios intangíveis: espirituais e religiosos, recreativos e ecoturísticos, etc.) e os serviços de suporte/ apoio (serviços necessários para a produção de todos os outros serviços dos ecossistemas (formação do solo, ciclos dos nutrientes, produção primária) (MEA, 2005).

No caso dos recursos hídricos, fatores como desperdício na utilização da água disponível, falta de planejamento hídrico e de saneamento por parte dos órgãos públicos, despejo de substâncias poluentes, etc., elevam a poluição das águas e contribuem para sua escassez.
Diante do exposto, tem-se que a resolução da problemática que envolve a utilização dos recursos hídricos depende da eficiência de sua gestão. No Brasil, foi implementada a Política Nacional de Recursos Hídricos (instituída pela Lei 9.433/97), que tem por objetivos, entre outros, a utilização racional e integrada dos recursos hídricos, de forma a assegurar seu uso adequado por gerações presentes e futuras em termos de quantidade e qualidade. Segundo a mesma, por meio da gestão descentralizada e participativa, deverão ser adotadas medidas que venham garantir o uso sustentável da água (Brasil, 1997).

Nesse sentido, além das tradicionais políticas baseadas no princípio poluidor-pagador, as entidades responsáveis pela gestão dos recursos hídricos vêm adotando políticas que incentivam a adoção de práticas capazes de contribuir para a recuperação e a preservação ambiental baseadas no princípio conservador-recebedor, permitindo que, por meio da ação humana, possam ser maximizadas as externalidades positivas e minimizadas as externalidades negativas geradas ao meio ambiente.

Como alternativa, desde o final da década de 1990, o Pagamento por Serviços Ambientais (PSA) vem sendo adotado como instrumento de mercado que objetiva a proteção ambiental (Wunder, 2005).

A metodologia do PSA consiste no pagamento de compensação financeira ao produtor que adote práticas em prol de melhorias ambientais especificadas em edital. Mais do que a compensação financeira, segundo Wunder (2005), para que um projeto possa ser classificado como PSA deve respeitar as seguintes condições: ser uma transação voluntária, ter um uso ambiental bem definido (ou um tipo de uso da terra que assegure este serviço), ser "comprado" por ao menos um provedor de serviços, ter pelo menos um provedor de serviços e o provedor (ofertante) deve assegurar a provisão do serviço prestado (condicionalidade).

No caso de experiências de PSA voltadas à recuperação e à conservação dos recursos hídricos, as ações prioritárias se referem à preservação de nascentes e da floresta próxima às mesmas. Conservando-se as estruturas ecossistêmicas, garantem-se resultados positivos em termos de "produção" de água e de manutenção dos componentes do bem-estar a ela associados. 
Uma das experiências de PSA já implantadas é o Programa Produtor de Água e Floresta (PAF) da cidade de Rio Claro/RJ. Localizado na região estratégica correspondente à cidade de Rio Claro, no Estado do Rio de Janeiro, o programa tem como objetivo aplicar o instrumento de PSA, motivando os produtores locais de forma financeira que comprovadamente contribuam ou implementem práticas para a restauração/preservação dos recursos naturais, como de mananciais e florestas, auxiliando a recuperação do potencial de geração de serviços ecossistêmicos, provendo benefícios às bacias hidrográficas e à sociedade em geral (ITPA, 2013).

A Bacia Hidrográfica do Guandu, na qual se localiza a área objeto do programa de PSA, segundo o relatório da Conjuntura dos Recursos Hídricos no Brasil divulgado em 2013, está em situação crítica em relação à disponibilidade e qualidade da água, fator que se deve em parte à elevada concentração populacional com altas demandas de uso urbano e industrial (ANA, 2013).

A importância do PAF se deve à área compreender as principais nascentes do rio Piraí, manancial responsável por $15 \%$ dos recursos hídricos disponíveis no sistema Guandu, responsável por cerca de $80 \%$ do abastecimento de água na cidade do Rio de Janeiro e região metropolitana (ITPA, 2013).

Para que os resultados obtidos por meio dessa e de outras experiências de PSA sejam satisfatórios e as externalidades positivas esperadas sejam efetivamente geradas, devem ser avaliadas informações acerca da mesma e dos agentes nelas envolvidos. Cabe ressaltar que o prévio conhecimento do perfil dos atuais e potenciais beneficiários do programa em questão, bem como de suas motivações para adesão e percepção acerca da importância do meio ambiente em si e de suas inter-relações com o seu bem-estar e de sua família, pode contribuir para o desenho/aprimoramento de programas de forma a torná-los mais atraentes e que tragam, por fim, a mudança de práticas em prol das melhorias ambientais.

Este estudo tem por objetivo discutir em que medida o perfil socioeconômico, a percepção quanto à sustentabilidade ambiental e sobre os serviços ecossistêmicos e a consciência ambiental dos produtores que integram o PAF determinaram sua participação no programa.
Pretende-se ainda avaliar, por meio da percepção dos mesmos, a implantação do programa e seus resultados.

\section{Materiais e Métodos}

\subsection{Caracterização do Programa Produtores de Água e Floresta}

O projeto Produtores de Água e Floresta (PAF) foi implantado no ano de 2009, em Lídice, distrito do município de Rio Claro/RJ, e tem como principal objetivo "proporcionar o aumento de cobertura florestal em áreas de preservação permanente e demais áreas prioritárias, melhorando a qualidade e a quantidade dos recursos hídricos dos mananciais" (ITPA, 2013, p. 3).

O marco legal da experiência se deu com a publicação, pela Prefeitura Municipal de Rio Claro, da Lei $514 / 2010$, que cria o projeto Produtor de Água e Floresta e autoriza o pagamento financeiro aos proprietários de Reservas Particulares do Patrimônio Natural (RPPNs), e na sua regulamentação, por meio da publicação do Decreto no 931 em julho de 2011.

Os proprietários ou detentores de imóveis rurais responsáveis pelo uso e manejo do solo nas cabeceiras das bacias contribuintes da região hidrográfica do Guandu são o público-alvo do programa e deverão, a partir de sua inclusão no projeto, receber compensação financeira por adotarem, contribuírem ou implementarem práticas para a proteção dos recursos naturais ou recuperação de mananciais, elevando o potencial de geração de serviços ecossistêmicos e, em consequência, melhorando as condições de vida da sociedade (ITPA, 2013).

Para se inscrever, o produtor deverá disponibilizar para restauração no mínimo $25 \%$ de área sem cobertura florestal de sua propriedade, que deverá estar situada em áreas prioritárias ao projeto. O percentual de área incluída no projeto é um dos critérios adotados para o cálculo do valor pago ao produtor, sendo maior o valor pago àqueles que disponibilizarem maior área. Além disso, deverão ser preenchidos e entregues formulários e documentação conforme estabelecido por edital de chamamento divulgado pela Prefeitura Municipal de Rio Claro. 
A experiência foi operacionalizada por meio da assinatura de um termo de cooperação técnica entre a Secretaria Estadual do Ambiente (SEA), a Prefeitura Municipal de Rio Claro, a The Nature Conservancy (TNC), o Comitê de Bacia Hidrográfica do Rio Guandu e o Instituto da Terra de Preservação Ambiental - ITPA (Unidade Gestora do Projeto - UGP), com o apoio da
Agência Nacional das Águas (ANA), sendo exemplo de gestão compartilhada dos recursos naturais (ITPA, 2013).

A importância da aplicação e efetividade de programas que visem à melhoria ambiental na região se deve à grande abrangência da bacia hidrográfica em estudo (Figura 1), que tem o potencial de utilização dos recursos hídricos para o atendimento das necessidades de cerca de doze milhões de pessoas no Estado do Rio de Janeiro

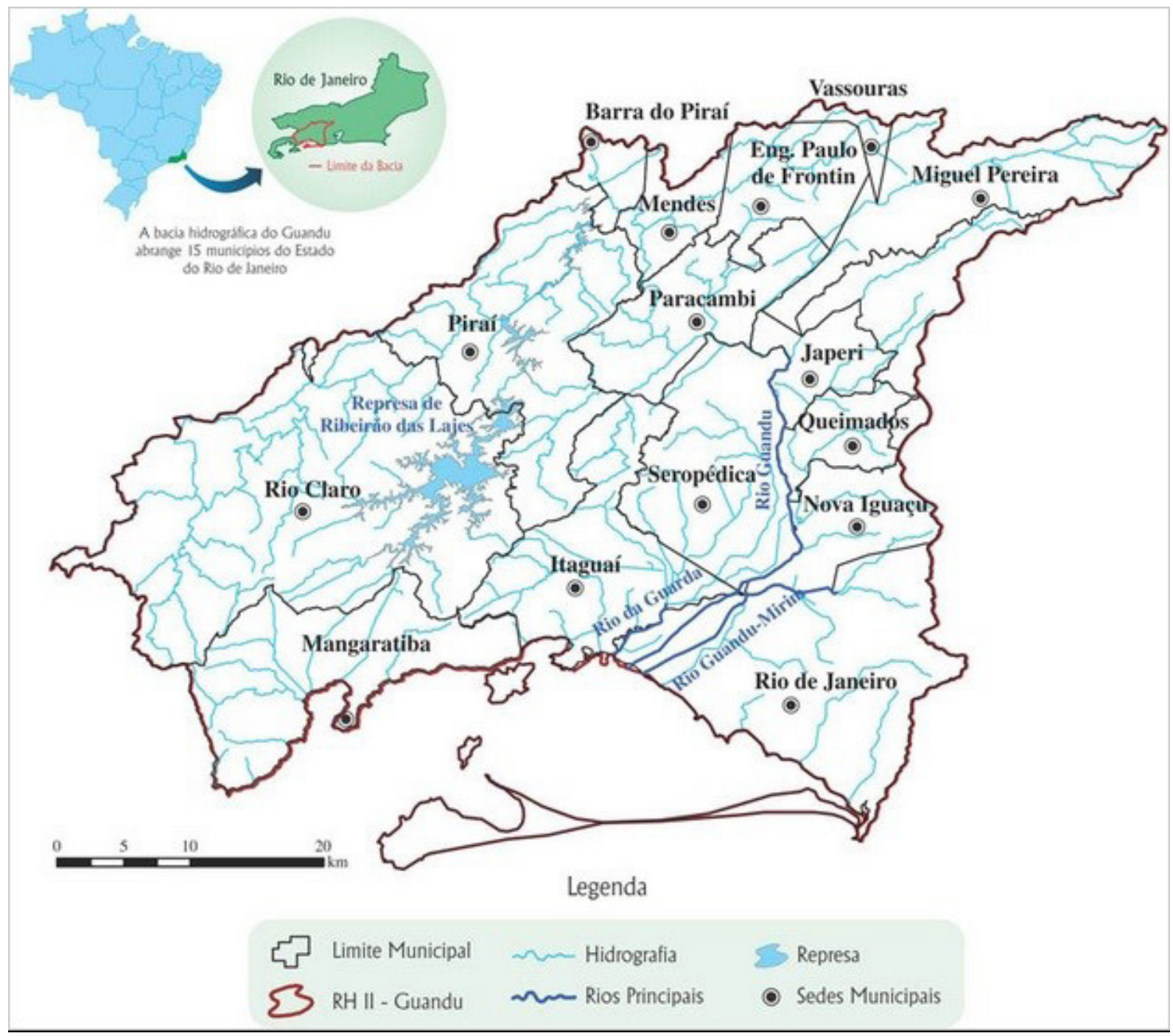

FIGURA 1 - Bacia Hidrográfica dos Rios Guandu, da Guarda e Guandu-Mirim.

FONTE: Comitê Guandu (2013). 
(70\% da população do estado) (Tiago, 2013). Além disso, pode-se contribuir para a preservação de diversos ecossistemas e espécies que dependem da conservação e da recuperação da estrutura ecossistêmica objeto do projeto.

O projeto-piloto já realizou pagamentos totalizando R\$ 331 mil a 59 proprietários rurais, cujos esforços já ajudaram a conservar 4.197 hectares de floresta e restaurar 494 hectares de terras degradadas (Tiago, 2013). Além da demanda atendida, a UGP dispõe de recursos financeiros para a inclusão de novas propriedades no programa, o que depende da maior procura por parte dos produtores da região.

Com vistas a, entre outros fatores, contribuir para a ampliação da experiência de PSA em Rio Claro, o The Nature Conservancy (TNC), em parceria com outras instituições, vem implantando o Cadastro Ambiental Rural (CAR) no município, o que resultará na melhoria das informações acerca das propriedades rurais na cidade, permitindo maior inclusão dos produtores no PAF (TNC, 2013).

Os valores recebidos pelos produtores são calculados a partir de um custo de oportunidade local associado a quatro parâmetros, sendo: a área destinada à conservação e restauração; o nível de prioridade para a produção de água na bacia piloto (APPs e Áreas Interceptoras de Água); estágio de sucessão dos remanescentes em conservação (avançado, médio ou inicial) e contexto geográfico de proximidade ou inclusão em áreas de conservação (ITPA, 2013).

A variação desses valores está entre $\mathrm{R} \$ 10,00$ a R \$ 60,00 por hectare/ano, entretanto, a UGP definiu que o valor mínimo a ser recebido por um associado, independente do tamanho da área restaurada/conservada, é de R\$ 100,00/ano, sendo o capital oriundo do pagamento pelo uso da água e outorga (direito do uso da água) administrado pelo Comitê de Bacia do Rio Guandu (criado a partir do Decreto $\mathrm{n}^{\mathrm{o}} 31.178$, de 03 de abril de 2002). Assim, uma parte dos recursos pagos pelos usuários da água é destinada ao pagamento dos proprietários responsáveis diretos pela "produção" de água².

O pagamento está condicionado a uma avaliação das atividades envolvidas e à apresentação de relatórios periódicos juntamente com o laudo de vistoria, possibilitando assim o monitoramento da área abrangida.

\subsection{Metodologia}

Para o atendimento dos objetivos propostos pela pesquisa, foram coletados e analisados dados primários e secundários. Inicialmente foi feita a consulta a referências bibliográficas relacionadas ao tema objeto de estudo.

Posteriormente, visando caracterizar o perfil socioeconômico dos produtores inscritos no programa, foram realizadas entrevistas semiestruturadas para obter informações que permitissem conhecer suas motivações para a adesão à experiência de PSA e captar sua percepção em relação ao meio ambiente e sua inter-relação com níveis de bem-estar. $\mathrm{O}$ contato dos produtores foi disponibilizado pelo ITPA, unidade gestora do projeto.

De um total de 59 produtores inscritos, conseguiu-se que 29 deles participassem da pesquisa e respondessem (via e-mail, telefone e entrevista pessoal) às perguntas propostas. As entrevistas foram realizadas no período de junho/2013 a setembro/2013.

Os resultados obtidos serão apresentados na próxima seção.

\section{Resultados e discussões}

\subsection{Quanto ao perfil socioeconômico}

Do grupo de produtores participantes da pesquisa tem-se que $28 \%$ ingressaram no projeto em 2009 , sendo os pioneiros (Tabela 1).

TABELA 1 - Percentual de produtores por ano de ingresso no PAF.

\begin{tabular}{cc}
\hline Ano & Percentual \\
\hline 2009 & 28 \\
2010 & 10 \\
2011 & 38 \\
2012 & 24 \\
\hline
\end{tabular}

\footnotetext{
${ }^{2}$ Maiores informações sobre o cálculo da remuneração para os produtores consultar ITPA (2013).
} 
Apesar de participarem do PAF, 28\% dos produtores não souberam responder qual é a área de sua propriedade incluída no programa. Segundo os que responderam a essa questão, a média de área incluída por propriedade é de 38,5 ha (sendo que em 7 propriedades $\mathrm{a}$ área incluída é menor que $10 \mathrm{ha}$ ).

Os resultados da pesquisa mostram ainda que a maioria dos produtores inscritos no PAF participantes da pesquisa é do sexo masculino (83\%), que 93\% têm idade acima dos 40 anos ( $45 \%$ acima de 60 anos) e que $45 \%$ deles concluíram o ensino superior ( $38 \%$ o ensino médio).

Observou-se que um nível significativo desses produtores tem nível superior completo (45\%), sendo que $83 \%$ da amostra analisada possui o equivalente a 12 anos de estudo, um padrão superior à média de 8,5 anos atribuída às pessoas maiores de 25 anos do Estado do Rio de Janeiro (IBGE, 2013a).

Outras informações importantes se referem às condições econômicas dos mesmos (Tabela 2).

Quanto ao nível de renda, verifica-se que 48\% dos produtores possuem renda familiar superior a $\mathrm{R} \$$ 3.390,00 (três mil trezentos e noventa reais), valor igual ou maior a 5 (cinco) salários mínimos, sendo o mesmo superior à renda média das famílias do Estado do Rio de Janeiro, que corresponde a R \$ 3.346,37 (três mil trezentos e quarenta e seis reais e trinta e sete centavos), de acordo com dados do IBGE (2008-2009) (IBGE, 2013b).

A maioria dos entrevistados não depende das atividades desenvolvidas na propriedade para se manter economicamente (90\% têm sua principal fonte de renda fora da atividade, sendo que do total $51,7 \%$ têm como renda principal a aposentadoria).

Apesar de não dependerem da renda gerada na propriedade, os produtores desenvolvem, na propriedade inscrita, de forma ativa, alguma atividade econômica. Dentre elas foram citadas a produção de milho, capim, as pecuárias de corte e de leite, a olericultura, as aviculturas de corte e de postura, a apicultura voltada para a produção de mel, a piscicultura, a minhocultura e a fruticultura.

Dos produtores entrevistados, $52 \%$ não residem na propriedade rural na qual o projeto PAF foi implementado. Dentre aqueles que moram na propriedade, observa-se a média de 24 anos residindo na mesma e cerca de três moradores em cada uma delas.

Resumidamente, os produtores entrevistados constituem, em sua maioria, um grupo de homens, que possui renda familiar e escolaridade acima das médias do Estado do Rio de Janeiro, não reside e não tem na propriedade sua principal fonte de renda e que, apesar disso, lá desenvolvem alguma atividade produtiva.

\subsection{Quanto à adesão ao PAF e suas motivações}

Conforme já especificado, a adesão ao PAF é voluntária, dependendo, portanto, do interesse do produtor em participar. Entender quais são os fatores determinantes para que o produtor participe efetivamente do mesmo, contribuindo para a eficácia do projeto, é fundamental.

TABELA 2 - Distribuição absoluta e relativa dos dados e econômicos.

\begin{tabular}{lccc}
\hline \multicolumn{1}{c}{ Variável } & Alternativas & $\begin{array}{c}\text { Número de } \\
\text { produtores }\end{array}$ & (\%) \\
\hline Renda Domiciliar & $1-5$ & 15 & $52 \%$ \\
(Salários mínimos)* $^{*}$ & $5-10$ & 8 & $28 \%$ \\
Principal fonte de renda & $>10$ & 6 & $20 \%$ \\
Desenvolve atividade econômica na & Dentro da propriedade & 3 & $10 \%$ \\
propriedade & Fora da propriedade & 26 & $90 \%$ \\
Reside na propriedade & Sim & 24 & $83 \%$ \\
& Não & 5 & $17 \%$ \\
\hline
\end{tabular}

Nota: * Baseado no salário mínimo de $\mathrm{R} \$ 678,00$. 
Fatores facilitadores e que dificultaram o processo também devem ser conhecidos.

Primeiramente buscou-se avaliar de que maneira os produtores ficaram sabendo da existência do projeto e da oportunidade de ingressar no mesmo. Para a maioria $(35 \%)$, as informações foram disponibilizadas pelo ITPA, órgão que gere o projeto, seguido dos próprios produtores (31\%) e da Prefeitura Municipal de Rio Claro (21\%). Observa-se que fontes públicas ou associações foram determinantes para a adesão desses produtores, indicando que essas instituições estão trabalhando para o sucesso do projeto e da melhoria das práticas ambientais adotadas na região.

Quando perguntados sobre a motivação para a adesão ao projeto, tem-se que $83 \%$ dos produtores declararam que foi a preocupação com a conservação ambiental. Para outros $14 \%$, o retorno financeiro foi fator determinante. Um dos produtores entrevistados (3\%) se manifestou contra o projeto e justificou sua adesão como imposta pelos outros proprietários da terra (a propriedade pertencia a três pessoas, sendo que duas delas foram favoráveis à adesão ao programa).

Quanto aos fatores que puderam facilitar ou dificultar a adesão dos produtores, tem-se que, para $49 \%$ dos entrevistados, a boa assistência técnica oferecida é o principal fator facilitador quando da adesão ao projeto, enquanto para $41 \%$ a facilidade se dá principalmente pela satisfatória disponibilidade de informações.

De maneira distinta, Oliveira et al. (2013), ao avaliarem alguns programas de PSA adotados no Estado de Minas Gerais, concluíram que para que os programas avaliados obtivessem sucesso seria necessária maior assistência técnica e melhor disponibilidade de informações para os produtores rurais, indicando que nessas experiências a assistência técnica e a transmissão de informação são deficientes.

Quanto às dificuldades, tem-se que 66\% dos produtores não apontaram nenhum fator capaz de dificultar a implantação do PAF, enquanto $17 \%$ acreditam que a burocracia para a adesão ao programa constitui em fator dificultador.

As facilidades e dificuldades apontadas indicam que a relação produtor/ITPA (responsável pela operacionalização do projeto), segundo os produtores, é adequada e contribui para o sucesso do mesmo. Alguns outros fato- res foram citados como fonte de dificuldades, entre eles a necessidade de se adotar práticas conservacionistas, as condições inadequadas das estradas e a falta de apoio. Apesar de pouco citados pelos produtores entrevistados, eles devem ser avaliados, buscando-se soluções por intermédio dos órgãos responsáveis.

As principais ações executadas pela equipe técnica nas propriedades foram a plantação de mudas e a construção de cercas (Tabela 3).

TABELA 3 - Principais ações executadas pela equipe técnica nas propriedades (percentual).

\begin{tabular}{lc}
\hline \multicolumn{1}{c}{ Ações } & $\begin{array}{c}\text { Percentual de } \\
\text { propriedades }\end{array}$ \\
\hline Plantação de mudas e construção de & 41 \\
cercas & \\
Plantação de mudas, construção & 41 \\
de cercas e recuperação de áreas & \\
degradadas & 12 \\
Plantação de mudas & 3 \\
Construção de ponte & 3 \\
Construção de um biodigestor & \\
\hline
\end{tabular}

Os produtores devem agir no sentido de conservar as melhorias executadas (que vão variar de acordo com um plano de trabalho para cada produtor), devendo reportar à unidade gestora local do projeto quaisquer danos que as mesmas venham a sofrer, bem como as áreas incluídas no programa (corte de árvores sem autorização legal, queimadas, etc.). A avaliação da participação dos produtores nesse sentido influenciará diretamente no valor pago pelos seus serviços prestados (ITPA, 2013).

Quando questionados quanto à adequação do valor pago pelo projeto ( $\mathrm{R} \$ 10,00$ a $\mathrm{R} \$ 60,00 / \mathrm{ha}$ ) pelas ações de conservação, $76 \%$ dos produtores declararam acreditar que o valor seja inadequado, devendo ser maior do que a remuneração atual.

A remuneração paga pelos projetos de compensação ambiental pode ser calculada a partir de diversos fatores. No caso do projeto em estudo (e de muitos outros), a mesma se baseia, em conjunto com outros fatores já descritos aqui, no custo de oportunidade da atividade produtiva na região, ou seja, o valor recebido calculado com base naquele que receberia caso ocupasse suas terras com a atividade econômica predominante nessa região. 
Infelizmente, esse valor é considerado insuficiente pelos produtores e acaba por não refletir a importância do recurso preservado pelos mesmos, podendo não ser considerado por outros produtores um atrativo para aderir ao projeto.

Segundo Pria et al. (2013), há dificuldade na implementação do PSA nas regiões rurais onde o preço da terra e a produtividade são altos justamente devido à dificuldade em se convencer produtores rurais a abrir mão de alguns hectares que trariam rentabilidade elevada para garantir que um determinado serviço ecossistêmico seja preservado.

O cálculo dos valores a serem pagos e a fonte de recursos para o financiamento dos mesmos são fatores que podem tornar inviável a implantação do programa de PSA ou mesmo determinar o insucesso das experiências já iniciadas. Para que sejam determinados preços considerados satisfatórios para os produtores, deveria ser avaliada sua disposição a receber para abrir mão do uso da terra e "ofertar" bens e serviços ambientais.

\subsection{Quanto à percepção da importância do meio ambiente para as espécies e da adoção de boas práticas ambientais}

Como já explicitado em resposta anterior, percebe-se que a maioria dos produtores entrevistados preocupa-se com as condições ambientais e que por isso aderiu ao projeto. Outro conjunto de perguntas aplicadas teve como objetivo captar a percepção dos produtores acerca da importância ambiental e de transformações ocorridas na natureza nos últimos anos na região.

Pretendeu-se também detectar aqueles que adotavam práticas conservacionistas ou que degradavam o meio ambiente antes da adesão ao projeto, visando avaliar a mudança de comportamento dos mesmos a partir do seu ingresso.

De acordo com as respostas obtidas, percebe-se que os produtores entrevistados conseguem associar sua adesão ao programa à "prestação de serviços ambientais" para a sociedade em geral. Segundo $76 \%$ deles, sua adesão contribuiria em termos de melhoria na qualidade do ar e da água, enfatizando o valor de uso dos recursos preservados (Tabela 4).

TABELA 4 - Percepção dos benefícios fornecidos à sociedade ao aderir ao programa PAF, segundo respondentes da pesquisa.

\begin{tabular}{lc}
\hline \multicolumn{1}{c}{ Benefício } & \% \\
\hline Exemplo de comportamento ambiental & 3 \\
Manutenção do habitat para outras espécies & 10 \\
Melhoria da qualidade do ar & 38 \\
Melhoria de qualidade das águas & 38 \\
Não acha que fornece nada & 3 \\
Todas as opções & 7 \\
\hline
\end{tabular}

Para $10 \%$, o principal benefício seria a manutenção do habitat para outras espécies, o que não estaria associado ao valor de uso direto ${ }^{3}$, indicando maior nível de consciência ambiental.

Outro fator importante avaliado foi se o produtor já adotava práticas de recuperação/conservação ambiental antes de se tornar membro do programa. Do total, $97 \%$ dos entrevistados informaram que já adotavam práticas em prol da melhoria ambiental, sendo as mais citadas: plantio de mudas, preservação de nascentes, cultivo de plantas, pomares e mudas, manutenção de áreas em reserva legal.

O produtor João Lopes Luiz Coelho, integrante desde 2009, se orgulha em dizer que possui 118 hectares de RPPN (Reserva Particular do Patrimônio Natural), a primeira RPPN do Rio de Janeiro, tendo consciência da importância da preservação ambiental para o bem-estar humano e da biodiversidade. O produtor ressaltou a importância do PAF na preservação dessa Reserva.

Quanto à degradação, 90\% declararam que não adotavam práticas que degradassem o meio ambiente. Daqueles que responderam afirmativamente a questão, $7 \%$ realizavam queimadas em suas propriedades e 3\% tinham criação extensiva de gado. Tais produtores declararam ter mudado suas práticas a partir da adesão ao PAF.

\footnotetext{
${ }^{3} \mathrm{O}$ valor de uso direto reflete o valor atribuído pelos indivíduos aos recursos naturais pelo uso direto dos mesmos. Como exemplo, temos o valor dos peixes retirados dos rios, a madeira retirada da floresta, a água extraída para a irrigação, a beleza de uma cena conferida por uma bela vista (MEA, 2005).
} 
Essas informações indicam que o programa em si contribuiu para a mudança de atitude de pequena parcela dos produtores no que se refere às ações voltadas à conservação ambiental, já que a maioria anteriormente à adesão já adotava tais práticas. Os resultados seriam mais efetivos caso produtores que adotassem práticas predatórias viessem a modificar suas ações.

Buscando captar a percepção dos produtores quanto às mudanças observadas nas matas nativas na região lhes foi perguntado se, nos últimos 20 anos, haviam observado alguma(s) mudança(s) nas mesmas.

Segundo as respostas, 93\% dos produtores afirmaram ter observado mudanças nas matas. Alguns poucos deram ênfase à redução da mata e dos córregos, mas a maioria observou o crescimento das matas, a recuperação de algumas áreas degradadas, o crescimento das árvores, o aparecimento de novas espécies de aves, o revigoramento de nascente na propriedade, entre outros.

Outra pergunta feita se referia aos impactos causados na atividade desenvolvida na propriedade devido às mudanças observadas na mata nativa. Do total, $17 \%$ declararam que as mudanças contribuíram positivamente na atividade, por meio de melhoria na disponibilidade de água e melhoria na plantação. Os demais (83\%) não observaram alterações na atividade devido às mudanças na mata.

Objetivando-se avaliar qual seria a percepção do produtor sobre a importância da mata nativa para o meio ambiente, perguntou-se qual seria, na sua percepção, a importância da mata nativa ao meio ambiente. A conservação da água foi apontada por $79 \%$ dos produtores como principal função da mata nativa (Tabela 5).

TABELA 5 - Importância da mata nativa para o meio ambiente, segundo respondentes da pesquisa.

\begin{tabular}{lc}
\hline \multicolumn{1}{c}{ Importância } & \% \\
\hline Conservação da água & 79 \\
Conservação da biodiversidade & 7 \\
Conservação da vida em geral & 3 \\
Conservação do solo & 3 \\
Qualidade do ar & 7 \\
\hline
\end{tabular}

Buscou-se captar ainda a importância atribuída à conservação da mata nativa para as pessoas. Nesse caso, $69 \%$ dos produtores associaram a importância da conservação da mata nativa à manutenção das condições de saúde humana (Tabela 6).

TABELA 6 - Importância da conservação da mata nativa para as pessoas, segundo respondentes da pesquisa.

\begin{tabular}{lc}
\hline \multicolumn{1}{c}{ Importância } & \% \\
\hline Manutenção das condições de saúde & 69 \\
Melhoria da qualidade da água & 21 \\
Melhoria do ar & 10 \\
\hline
\end{tabular}

Quando questionados sobre de que maneira o programa mudou sua vida, $45 \%$ dos produtores citaram que agora têm maior consciência ambiental e $45 \%$ destacaram as melhorias obtidas por meio da melhoria ambiental: água, ar, etc. Apenas 10\% deles indicaram o maior retorno financeiro da propriedade como fator de mudança.

Quanto ao valor monetário atribuído à propriedade, tem-se que $59 \%$ acreditam que o valor de mercado da propriedade aumentou a partir da implantação das ações estabelecidas pelo programa, enquanto $28 \%$ acreditam que não (13\% não souberam responder).

Por meio desse grupo de perguntas, pode-se perceber que os produtores integrantes do programa avaliado conseguem perceber a importância da preservação ambiental e sua associação à manutenção da qualidade de vida para as pessoas e, em menor grau, para outras espécies. E, mais importante, executam (e mesmo antes da adesão) ações em prol da recuperação e conservação ambiental.

Isso indica que a conscientização da população e dos produtores é fundamental para o sucesso das políticas ambientais que adotam mecanismos compulsórios, mas principalmente para aqueles que dependam da adesão voluntária.

\section{Considerações finais}

A resolução dos problemas que envolvam os recursos hídricos depende da adoção de medidas que venham induzir ações que contribuam para sua recuperação e conservação por parte do poder público e da sociedade, já que seu padrão de utilização há muito não se sustenta. 
Nesse contexto, o projeto Produtor de Água e Floresta implantado na cidade de Rio Claro é uma experiência que vem contribuindo para a adoção de ações práticas que visem à melhoria das condições ambientais, gerando efeitos locais e regionais.

Segundo Vilar et al. (2013), além das áreas já restauradas e conservadas, o projeto já apresenta resultados socioeconômicos positivos, sendo gerador de postos de trabalho na região e movimentando o comércio de maneira direta (compra de materiais necessários para a execução das melhorias nas propriedades) e indireta, por meio das compras possibilitadas pela renda gerada aos produtores.

Segundo os resultados da pesquisa, tem-se que maioria dos produtores que aderiu ao projeto já adotava práticas de conservação e optou em participar pela consciência ambiental que já tinham. Isso mostra a necessidade de se estimular proprietários que ainda não sejam adeptos de tais práticas a integrar o projeto, elevando seu ganho marginal.

Para tanto, os incentivos fornecidos devem ser mais atraentes. Segundo os produtores, os valores pagos são baixos e acabam por não estimular a adesão de novos integrantes. Esse fator dificulta o sucesso do projeto, já que não consegue influenciar a mudança de atitude dos produtores que ainda não se preocupam com a questão ambiental.

Outro fator importante a ser considerado seria o fato de que, entre os entrevistados, apenas dois utilizam a propriedade como fonte principal de renda da família. Como os demais não dependem economicamente da atividade desenvolvida na propriedade, os custos de oportunidade incorridos com a adesão seriam menores, incentivando sua participação.

\section{Referências}

ANA - Agência Nacional das Águas (Brasil). Conjuntura dos recursos hídricos no Brasil 2013. Brasília, 2013.

Brasil. Lei no 9.433, de 8 de janeiro de 1997. Brasil, 1997. Disponível em: <http://www.planalto.gov.br/ccivil_03/Leis/ L9433.htm>. Acesso em: 15 abr. 2014.
Para aqueles produtores que dependem da atividade na propriedade para a manutenção econômica da família, a questão do valor pago deve ser determinante para a adesão. A obrigatoriedade não seria uma opção, já que, metodologicamente, os projetos de PSA devem ser de adesão voluntária (Wunder, 2005).

Por fim, tem-se que o grupo de produtores considerados na pesquisa percebe o meio ambiente como determinante para o seu bem-estar, de sua família e de outras espécies, dando importância, portanto, aos serviços ecossistêmicos que os afetam direta ou indiretamente.

De acordo com as informações levantadas, o sucesso da implantação da experiência de PSA considerada no estudo se deveu, em grande parte, à conscientização ambiental dos produtores e à disponibilização de informações e assistência técnica por parte das instituições responsáveis pela mesma. Esses fatores também serão responsáveis pela manutenção das ações de recuperação/ conservação a médio e longo prazos, contribuindo de maneira decisiva para a melhoria dos recursos naturais na região, principalmente no que se refere às melhorias na disponibilidade e qualidade dos recursos hídricos.

Maior fiscalização das propriedades integrantes do PAF foi citada por alguns produtores como necessária para que os resultados esperados sejam efetivamente alcançados, o que indica que alguns dos produtores podem estar adotando práticas destrutivas em suas terras, mesmo já estando comprometidos com as metas do projeto.

A questão do cálculo do valor pago aos produtores pela prestação de serviços ambientais apresenta-se, segundo os entrevistados, como principal entrave ao aumento do número de adesões, devendo ser revista para que a experiência de PSA possa ser referendada como instrumento eficiente de política na gestão dos recursos hídricos na região.

Comitê Guandu. Atuação: bacias hidrográficas dos rios Guandu, da Guarda e Guandu-Mirim. Disponível em: <http://www.comiteguandu.org.br/hidrografica.php>. Acesso em: 10 out. 2013.

Costanza, R.; D’Arge, R.; De Groot, R.; Farber, S.; Grasso, M.; Hannon, B.; Limburg, K.; Naeem, S.; O’Neill, R. V.; Paruelo, J.; Raskin, R. G.; Sutton, P.; Van Den Belt, M. The value of the world's ecosystem services and natural capital. Nature, 387, 253-260, 1997. 
Daly, H.; Farley, J. Ecological Economics: Principles and applications. Washington, D.C.: Island Press, 2003.

De Groot, R. S.; Wilson, M. A.; Boumans, R. M. J. A typology for the classification, description and valuation of ecosystem functions, goods and services. Ecological Economics, 41, 393-408, 2002.

IBGE - Instituto Brasileiro de Geografia e Estatística. Números referentes à educação no Brasil: Estado do Rio de Janeiro. Disponível em: $<$ http://www.todospelaeducacao.org. br/educacao-no-brasil/numeros-do-brasil/dados-por-estado/ rio-de-janeiro/>. Acesso em: 25 out. 2013a.

IBGE - Instituto Brasileiro de Geografia e Estatística. Pesquisa de Orçamentos Familiares 2008-2009 - Despesas e Rendimentos. Disponível em: <http://www.ibge.gov.br/estadosat/ temas.php? sigla $=$ rj\&tema $=$ pofdespesasrendimentos $>$. Acesso em: 25 out. 2013 b.

ITPA - Instituto Terra de Preservação Ambiental. Produtores de Água e floresta. Disponível em: <http://www.itpa.org. br/?page_id=497>. Acesso em: 25 jan. 2013.

MEA - Millennium Ecosystem Assessment. Ecosystems and human well-being: Synthesis. Washington, D.C.: Island Press, 2005.

Oliveira, A. C. C. O.; Vilar, M. B.; Jacovine, L. A. G.; Santos, M. O.; Jacon, A. D. Histórico e implementação de sistemas de Pagamentos por Serviços Ambientais no Estado de Minas Gerais. Sustentabilidade em Debate, 4(1), 139-160, 2013.

Pria, A. D.; Diederichsen, A.; Klemz, C. Pagamento por Serviços Ambientais: uma estratégia para a conservação ambiental nas regiões produtoras no Brasil? Sustentabilidade em Debate, 4(1), 317-340, 2013.

Rio Claro (RJ). Lei Municipal $n^{\circ} 514$, de 29 de dezembro de 2010. Cria o projeto Produtor de Águas e Florestas, autoriza o executivo a prestar apoio financeiro aos proprietários de RPPN's e dá outras providências. Rio Claro: Câmara Municipal, 2010.

Rio Claro (RJ). Decreto $n^{\circ} 931$, de 01 de julho de 2011. Regulamenta a Lei Municipal no 514, de 29 de dezembro de 2010, e dá outras providências. Rio Claro: Câmara Municipal, 2011.

Tiago, A. Aves retornam às matas do Sistema Guandu e atestam a qualidade da floresta que a TNC ajuda a conservar. 2013. Disponível em: <http://www.tnc.org.br/nossas-historias/ destaques/aves-atestam-boa-qualidade-floresta-bacia-guandu. xml>. Acesso em: 10 out. 2014.

TNC - The Nature Conservancy. Serviços de georreferenciamento de imóveis rurais para fins de elaboração de Cadastro Ambiental Rural-CAR - no município de Rio Claro do Estado do Rio de Janeiro. 2013. Disponível em: $<$ http://www.tnc.org. $\mathrm{br} /$ quem-e-a-tnc/trabalhe-com-a-tnc/tdr-georreferenciamento-imoveis-rurais-car-rio-claro.pdf $>$. Acesso em: 10 out. 2014.

Vilar, M. B.; Bustamante, J.; Ruiz, M. Produtores de água e floresta, Rio Claro, Rio de Janeiro. In: Tubbs Filho, D.; Antunes, J. C. O.; Vettorazzi, J. S. (Org.). Bacia Hidrográfica dos Rios Guandu, da Guarda e Guandu-Mirim: experiências para a gestão dos recursos hídricos. Rio de Janeiro: INEA, 2012.

Wunder, S. Payments for Environmental Services: Some Nuts and Bolts. CIFOR, Occasional Paper $N^{\circ}$ 42, 2005. 